potential for confounding by severity when an unmatched control group is used. A similar problem occurred in the Saskatchewan study, ${ }^{7}$ which also used an unmatched control group. When this problem is corrected, however, either by using an appropriate control group (group A) or by adjusting for markers of asthma severity (table, top of p574), then the association of asthma drugs in general with deaths from asthma tends to disappear, whereas the findings for fenoterol remain firm (a similar pattern occurred in the Saskatchewan data $\left.^{7}\right)$. The table shows that control group A provides an adequate match for asthma severity, whereas some confounding exists in the unadjusted results for control group B. We drew this conclusion in the published paper, ${ }^{5}$ and Dr Lanes and his coworkers have simply repeated our analysis but misrepresented our conclusions.

When the hazards of fenoterol are being considered it is important that all of the evidence should be considered. There is now a wealth of epidemiological, experimental, and clinical evidence that fenoterol is more hazardous than other commonly used $\beta$ agonists. ${ }^{2}$ The second New Zealand mortality epidemic started when fenoterol was introduced in 1976, and continued until our first study was published in 1989; the death rate then fell by one half, and is now similar to that in other countries. It is important to search for alternative explanations, but the evidence increasingly indicates that confounding by severity is not a plausible explanation, and that the association between fenoterol and deaths from asthma is likely to be causal.

NEIL PEARCE JULIAN CRANE RICHARD BEASLEY CARL BURGESS Department of Medicine,

Wellington School of Medicine Wellington, New Zealand RODNEY JACKSON

Department of Community Health, Auckland Medical School, University of Auckland,
Auckland, New Zealand

1 Pearce NE, Beasley R, Burgess C, Grainger J, Crane J. Confounding by severity does not explain the association between fenoterol and asthma death [abstract]. Med $J$ Aust NZ 1990;20 (suppl):515.

2 Pearce NE, Crane J, Burgess C, Jackson R, Beasley R. Beta agonists and asthma mortality: déjà vu. Clin Exp Allergy 1991;21:40110.

3 Cox B, Elwood JM. The effect on the stratumspecific odds ratios of non-differential misspecific odds ratios of non-differential mislevels. Am J Epidemiol 1991;133:20-7.

4 Crane J, Pearce NE, Burgess C, et al. Markers of risk of asthma death or readmission in the 12 months following a hospital admission for asthma. Int J Epidemiol (in press).

5 Grainger J, Woodman K, Pearce NE, et al. Prescribed fenoterol and death from asthma in New Zealand, 1981-7: a further case-control New Zealand, 1981-7: a further
study. Thorax 1991:46:105-11.

6 Poole C, Lanes SF, Walker AM. Fenoterol and fatal asthma [letter]. Lancet 1990;i:920.

7 Spitzer WO, Suissa S, Ernst P, et al. The use of beta-agonists and the risk of death and nea death from asthma. $N$ Engl J Med 1992; 326:501-6.

Pleural abrasion: a new method of pleurodesis?

Pleural abrasion, as a means of pleurodesing the lung, is not a new technique, as implied by the paper of Mr UU Nkere and others (August 1991;46:596-8). We and most thoracic surgeons in Australia have been performing transaxillary thoracotomies, apical bullae stapling and abrasive pleurodesis for at least 20 years. At the Prince Charles Hospital-a cardiothoracic hospital serving Queensland-in the period January 1985-December 1990, 320 patients were operated on in our thoracic surgical service for spontaneous pneumothorax. The mean age was 28 years and $M: F$ ratio was $1 \cdot 4: 1$.

Surgery was performed via the following surgical approaches: transaxillary thoracotomy (TAT) 244 patients, bilateral TAT 12 patients, lateral thoracotomy 52 patients, anterior thoracotomy 6 patients, posterolateral thoracotomy 6 patients. Pleurodesis was achieved thus: pleural abrasion 185 patients, talc with or without abrasion 42 patients, pleurectomy 84 patients, talc with or without pleurectomy 4 patients, other or unknown 5 patients. The mean postoperative hospital stay was four days. There were recurrences requiring surgery in 20 patients and recurrences not requiring surgery in three patients.

I think you must agree that from our experience pleural abrasion is not a new method. We agree, however, with the authors that it is a highly suitable technique with good results. If combined with a transaxillary approach - often an incision no more than 2 inches $(5 \mathrm{~cm})$ wide - it is a cosmetically acceptable form of management for spontaneous pneumothorax, and we will continue to use this procedure.

P COLE

K S MATAR

Department of Thoracic Surgery, Prince Charles Hospital, Chermside, 4032 Queensland, Australia

AUTHORS' REPLY We are grateful to Drs Cole and Matar for sharing their extensive experience of surgery for pneumothorax with us. It was with some misgivings that we accepted the editorial decision to change the original title of our paper from "A safe and effective method of pleurodesis" to "New method ...." The only aspect of the technique which, as far as we are aware, has not been previously described is the use of a domestic pan scourer to achieve pleural abrasion and even this is not our invention, as it was being used by Mr Angus MacArthur at King's College Hospital 20 years ago. Despite the fact, however, that pleural abrasion has been in widespread use in North America and, as we now know, in Australia for many years not many surgeons using the technique routinely have published their results, and in the United Kingdom there remains the belief outside a small circle of thoracic surgeons and enlightened chest physicians that surgery for pneumothorax calls for a full pleurectomy through a large and painful incision. Indeed, it was the inaccurate and sometimes alarming perception that many of our patients had appeared to receive that prompted us to put our experience together, and in that the subject seems now to have received a wider medical airing than before ${ }^{1}$ our principal objective has, in part, been fulfilled. $S$ W FOUNTAIN Thoracic and Cardiac Surgical Unit, Harefield Hospital,
Harefield UB $6 \mathrm{JH}$

1 Anonymous. Pan scourer pleurodesis for pneumothorax [editorial]. Lancet 1992;i:217.

\section{Shunting through a patent foramen ovale}

The phenomenon of shunting through patent foramen ovale, as recently reported by Dr L Berry and others (January 1992;47:601), has interested me for some time.

Those authors emphasised the important point that the shunt flow was detected by transoesophageal echocardiography but not by transthoracic echocardiography - this is not recognised by all echocardiologists. A characteristic feature of this syndrome is platypnoea and orthodeoxia - that is, more pronounced breathlessness and hypoxaemia in the upright than in the supine position. Thus the shunt measurements should probably be made with the patient in the upright position if possible.

The incidence of probe patient foramen ovale is about $25 \%,{ }^{2}$ but so long as left atrial pressure exceeds right atrial pressure the valve leaflet acts as a closing flap. In the fetus the inferior vena cava empties anatomically and functionally through the foramen ovale into the left heart. In the adult a probe patent foramen ovale is most easily penetrated with a cardiac catheter passed from a femoral vein, not from the brachial vein. Unfortunately $\mathrm{Dr}$ Berry and her colleagues did not state which approach they used in their catheterisation.

For two reasons I doubt their explanation that the mechanism for the shunt is caused by mediastinal distortion caused by right pneumonectomy. Firstly, as mentioned above, the normal anatomy favours blood flow from the inferior vena cava to the left heart when the flap is pressed open. Secondly, this type of shunt occurs also after left pneumonectomy ${ }^{3}$ and after severe respiratory failure in chronic obstructive lung disease. ${ }^{4} \mathrm{~A}$ more likely mechanism of the different shunting in different positions is the changing relation between the right and the left atrial pressures. This, in turn, depends on the function curves of the right and left ventricles ${ }^{5}$ : apparently they cross, so that at low "venous return" right atrial pressure exceeds left atrial pressure, and at higher "venous return" left atrial pressure exceeds, or approaches, right atrial pressure.

ERIK BERGLUND Renströmska Sjukhuset, S-402 64 Göteborg, Sweden

1 Berglund E. Right-to-left intracardiac shunt in bstructive lung disease. Eur $J$ Respir Dis obstructive lung

2 Hagen P, Scholz D, Edwards W. Incidence and size of patent foramen ovale during the first 10 decades of life. Mayo Clin Proc 1984;59:17-20.

3 Roos CM, Romijn KH, Braat MCP, van Leeuwen AM. Posture-dependent dyspnea and cyanosis after pneumonectomy. Eur $J$ Respir Dis 1981;62:377-82.

4 Begin R, Gervais A, Guérin L, Buriau MA. Patent foramen ovale and hypoxemia In COPD. Eur J Respir Dis 1981;62:373-6.

5 Berglund E. Ventricular function. VI. The balance of left and right ventricle output: relationship between left and right atrial pressures. Am J Physiol 1954;178:381-6.

Persistent alveolar increased permeability to ${ }^{99}$ Tc DTPA in patients with advanced HIV infection

In their paper regarding the diagnostic value of lung clearance of ${ }^{99 \mathrm{~m}}$ Tc DTPA in Pneumocystis carinii pneumonia Dr D S Robinson and his colleagues (October 1991;46:722-6) emphasised the specificity of the shape of the clearance curve by noting that none of their patients who did not have pneumocystis pneumonia had a biphasic curve in both the upper and the lower zones of the lung.

We have observed three HIV infected homosexual men who did not have pneumocystis pneumonia in whom ${ }^{99 \mathrm{~m}} \mathrm{Tc}$ DTPA transfer time (mean (SE) $\mathrm{T}_{50}$ ) ranged from $3 \cdot 1$ to 4.6 (mean 4.3 ) minutes and was biphasic in the upper, mid and lower zones over a follow up period of four, 18, and 31 weeks. This compares with a mean ${ }^{99 m}$ Tc DTPA transfer time in five HIV patients with pneumocystis pneumonia of $3 \cdot 1$ (1.4) (range 1.8-9.6) minutes and is significantly lower than transfer times in HIV positive patients with various non-pneumocystis pneumonia chest condi- 